\title{
The first year as a nurse practitioner: An integrative literature review of the transition experience
}

\author{
Nicole Twine* \\ Houston Methodist Hospital, Houston, Texas, United States
}

Received: July 10, 2017

DOI: $10.5430 /$ jnep.v8n5p54
Accepted: August 14, 2017

Online Published: December 20, 2017

\begin{abstract}
The purpose of this integrative literature review was to synthesize current knowledge about the role transition from new graduate Nurse Practitioner (NP) to novice NP to increase our understanding of how to better support NP entry into practice. The NP role was implemented in the United States over fifty years ago and has proven to contribute to patient outcomes and reduced health care costs. Proper transition experience to advanced practice nursing is fundamental to these improved patient outcomes in the hospital setting. The transition from Registered Nurse to professional NP is an important and difficult adjustment to make and may affect ongoing NP practice. The following topics were reviewed: graduate NP to novice NP transition, NP perception of preparedness, and perceived challenges encountered during role transition. A search for relevant literature was conducted in the EBSCO Host and ProQuest databases and in the Cumulative Index to Nursing and Allied Health Literature (CINAHL), PubMed, and MEDLINE specialty databases. Ten articles were identified and 3 major topic areas were revealed in the analysis: role transition, perception of preparedness, and perceived challenges. Establishing role identity as an NP, developing professional relationships, and having effective mentorship emerged as key issues influencing the transition process. Training programs are rare. A need exists for additional support and education for new hospital based NPs as they transition from students to practicing clinicians. Future studies that focus on the transition experience after internships programs may provide insight into how to develop or modify educational programs for NPs that will improve or enhance their transition to expert practitioner practice.
\end{abstract}

Key Words: Nurse practitioner, Role transition, Transition experience, Literature review

\section{INTRODUCTION}

There are more than 222,000 nurse practitioners (NPs) licensed in the United States, $86 \%$ of whom are prepared to deliver primary care. ${ }^{[1]}$ An estimated 20,000 new NPs completed their academic programs in 2014-2015. ${ }^{[1]}$ The NP role was implemented in the United States over fifty years ago. A shortage of pediatricians to provide care in rural areas motivated Dr. Loretta Ford and Dr. Henry Silver to develop an elevated nurse role to provide care provide for those pediatric patients. Their partnership resulted in the development of the first NP certificate program at the University of Colorado in the mid-1960s. From that initial program, the
NP profession has blossomed into board certified and state recognized graduate degree programs all across the United States (US), specifically family, acute care, and women's health, neonatal, psychiatric, and adult/gerontological. Currently, over 50 countries have been identified as developing or having existing advanced practice nurse (APN)/NP roles. APN models are being created within the context of each individual country, and the model of practice, titling, scope and standards of practice and education, vary extensively from country to country. The Acute Care Nurse Practitioner (ACNP) role evolved in the 1990s in the United States to fill the health care gaps created by changes in resident education.

*Correspondence: Nicole Twine; Email: nltwine2@HoustonMethodist.org; Address: Houston Methodist Hospital, Houston, Texas, United States. 
Since that time, the number of ACNPs has grown to approximately $17,000,{ }^{[1]}$ with $62 \%$ of their care delivered in the hospital setting. ${ }^{[2]}$ Currently, the curriculum in many ACNP programs lacks specialty training in any particular area, but focuses on acute processes across the life-span. Specialty training has been delegated to on-the-job training or continuing education provided by professional organizations after graduation. ${ }^{3]}$ Transition programs for new NPs are rare. Although there are over 30 postgraduate residency programs, there are no pre-graduate internship programs. NPs report the need for additional support and education as they transition from students to practicing NPs. ${ }^{[4]}$ According to the 2011 Institute of Medicine (IOM) report The Future of Nursing: Leading Change Advancing Health, nurses should be change advocates who care for populations within complex health care systems. ${ }^{[5]}$ The IOM reports states, "advanced practice registered nurses (APRNs) should be able to practice to the fullest extent of their education and training."[5] Internship programs for NPs are rare, and there is a need for additional support and education for new NPs as they transition from students to practicing NPs. ${ }^{[4]}$ Proper transition experience to advanced practice nursing is fundamental to improved patient outcomes. The purpose of this literature review was to synthesize current knowledge about role transition from novice to expert NP and to increase our understanding of how to support NP entry into practice. The following topics were reviewed: graduate NP to novice NP transition, NP perception of preparedness, and perceived challenges encountered during role transition.

\section{Methods}

A search for relevant literature was conducted in the EBSCO Host and ProQuest databases and in the Cumulative Index to Nursing and Allied Health Literature (CINAHL), PubMed, and MEDLINE specialty databases. Key words or phrases used in the search were registered nurse to nurse practitioner transition, nurse practitioner role transition, nurse, and transition into practice. Searches were limited to English-language and peer-reviewed scholarly journals. Several organizations were accessed for relevant research. These included the Agency for Health Care Research and Quality, American Nurses Association, American Association of Colleges of Nursing, American College of Nurse Practitioners, and American Academy of Nurse Practitioners. Reports from the IOM provided foundational information. The studies included in this review met the following inclusion criteria:

(1) NP role transition was a research variable.

(2) Participants were new NPs who had experienced role transition.

(3) Studies were written in English.

Initially, the search range was limited to 10 years, but due to limited literature it was extended to 20 years. Studies of Registered Nurses (RNs) were excluded. Ten articles were included in this review. The PRISMA flow chart for study selection is shown in Figure 1.

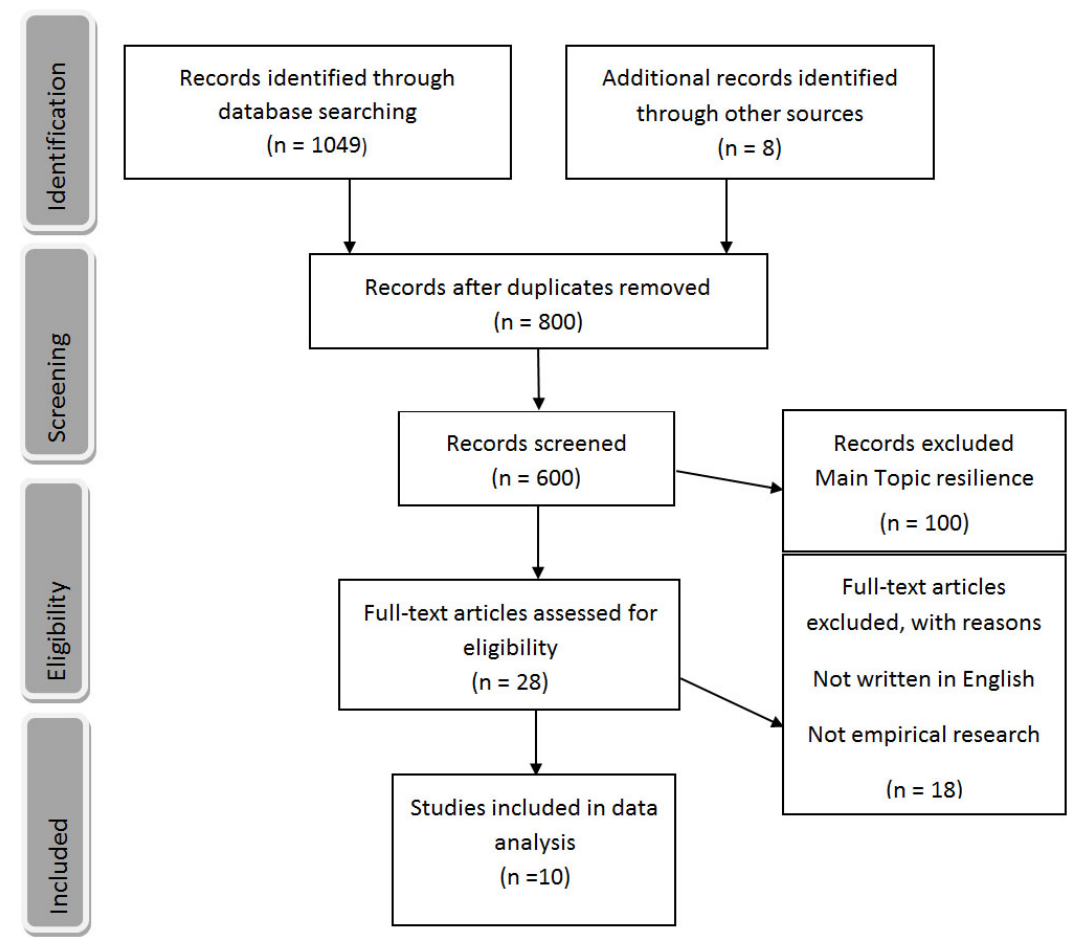

Figure 1. Prisma table 


\section{RESUlts}

Analysis of the 10 articles revealed 3 major topic areas: role transition, perception of preparedness, and perceived challenges. Establishing role identity as an NP, developing professional relationships, and having effective mentorship emerged as key issues influencing the transition process. Not feeling prepared, wanting more training, and using past nursing experience to fill knowledge gaps related to the perception of preparedness. Perceived challenges included dealing with applying for licensure and developing new relationships with coworkers and patients who might be unfamiliar with the role of the NP. The studies included in the analysis are summarized in Table 1.

\subsection{Nurse practitioner role transition}

The transition from RN to professional NP is an important and difficult adjustment to make and may affect ongoing NP practice. According to Brown and Olshansky, ${ }^{[6]}$ new graduates undergo an actual transition period as they enter into NP practice. The first year of practice is considered very important in the transition phase. ${ }^{[6]}$ During this adjustment period, many NPs report finding it difficult to make the transition from that of an experienced RN to a novice NP. The adjustment in professional identity can impact self-confidence, impair development of the new role, and influence decisions to remain in the job and in the profession within the first year of clinical practice for new NPs. ${ }^{[7]}$ Role development is a key aspect of a successful transition. ${ }^{[8]}$ With the expansion of new APN/NP roles across the globe, understanding transition to NP practice could be a key component. The transition begins when the student prepares to enter school and sees herself or himself in the NP role. ${ }^{[9]}$

Brown and Olshansky ${ }^{[6]}$ conducted a longitudinal, qualitative study with 35 newly graduated primary care NPs. The NPs were interviewed 3 times during their first year of practice: at 1 month, at 6 months, and again at 1 year after graduation from their NP academic program. The study revealed many themes about the novice NP stages of development. The first theme identified was "laying the foundation" (recuperating from school, negotiating the bureaucracy, looking for a job, and worrying). The second theme was "launching" (feeling real, getting through the day, battling time, and confronting anxiety). The third theme was "meeting the challenge" (increasing competence, gaining confidence, and acknowledging system problems). The last theme was "broadening the perspective" (developing system savvy, affirming oneself, and upping the ante). NPs claimed identity confusion, which affected the development of their self-confidence. During the first year, as NPs became more comfortable with their new roles, self-confidence increased. During the first 6 months of employment, NPs experienced negative interactions because coworkers lacked knowledge of the NP role and NPs were expected to work autonomously before having adequate time to adjust to their new role.

Kelly and Matthews ${ }^{[9]}$ conducted a qualitative descriptive study in which they interviewed 21 recent NP graduates. The purpose of this study was to obtain a better understanding of the transitional phase in the NP's first position after graduation. These authors identified several themes in their analysis. One was a loss of personal control of time, which the NPs perceived as a loss of personal time and privacy. A second theme concerned changes and losses in relationships. The NPs described changes in their relationships with nurses and how they were treated. Having a good physician mentor instilled self-confidence. The third theme was feelings of isolation. The NPs felt they were pioneers in practice. They felt somehow they were doing it alone. The last theme identified was the uncertainty in establishing the NP role. Adding to the uncertainty, scope of practice varied between states and keeping up to date with new medical knowledge was a challenge. Understanding what was now in their scope of practice was a big component of this theme.

Heitz et al. ${ }^{[7]}$ conducted a descriptive qualitative study using telephone interviews to examine the role transition from an RN to a Family Nurse Practitioner (FNP). Participants included 9 recent FNP graduates from a university in western United States, who were recruited from 1996-2001. The researchers developed the Role Transition Conceptual Model from the concepts and themes that emerged. The model included 2 role transition phases at its core and 6 central categories. Phase I of transition was the educational phase. Six participants reported that FNP role transition did not happen during their formal education process. They indicated that it did not take place until after graduation. The subcategories in Phase I included turbulence and extrinsic and intrinsic obstacles. Turbulence was defined as alternating between many emotions. Intrinsic obstacles occurred in response to external stressors and included feelings of fear, insecurity, and role confusion. Extrinsic obstacles in the clinical sites were related to events, situations, or people. Clinical site negativity was related to lack of ineffective preceptors and proper mentoring. Phase II was the post-graduation phase, ranging from 6 months to 2 years. In Phase II, the NP had entered into the work setting. Phase II included the following subcategories: positive intrinsic forces, positive extrinsic forces, and role development. As turbulence from Phase I was encountered, it produced reliance in positive forces. Each phase explained how obstacles stimulated emotional responses that caused the NP to rely on positive forces. 
Table 1. Literature review table

Design Findings

\begin{tabular}{|c|c|}
\hline Reference & Sample/Setting \\
\hline $\begin{array}{l}\text { Hart \& } \\
\text { Macnee } \\
\text { (2006) }\end{array}$ & $\begin{array}{l}\text { The questionnaires were administered to } \\
\text { attendees at two large national NP conferences } \\
\text { in } 2004 \text { in Cheyenne Wyoming. A total of } 562 \\
\text { questionnaires were completed and used in the } \\
\text { analysis. The sample contained } 94 \% \text { (N-527) } \\
\text { women with average age } 49 \text {. Nurse practicing as } \\
\text { an APN for average } 11 \text { years }\end{array}$ \\
\hline $\begin{array}{l}\text { A. Faraz, } \\
(2015)\end{array}$ & $\begin{array}{l}\text { Convenience sample of } 177 \text { NPs of NPs } \\
\text { practicing in PC settings was recruited through } \\
\text { all Commission on Collegiate Nursing } \\
\text { Education (CCNE) accredited master's nursing } \\
\text { programs, social media sites, and snowballing. } \\
\text { A total of } 29 \text { NP educational programs from all } \\
\text { regions of the United States and five NP } \\
\text { residency/fellowship programs forwarded the } \\
\text { e-mail to their graduates. }\end{array}$ \\
\hline $\begin{array}{l}\text { Barnes, } \\
(2015)\end{array}$ & $\begin{array}{l}\text { Convenience sample of } 352 \text { participants at a } \\
\text { national NP conference. Inclusion criteria } \\
\text { included NPs who are currently practicing in } \\
\text { direct patient care within the US, hold a } \\
\text { graduate degree to practice as an NP, are able to } \\
\text { speak and read English, and have been working } \\
\text { as an NP for at least } 6 \text { months because role } \\
\text { transition after graduation and into the first } \\
\text { position can. }\end{array}$ \\
\hline $\begin{array}{l}\text { Dillon et al. } \\
(2016)\end{array}$ & $\begin{array}{l}\text { The study included a convenience sample of } 34 \\
\text { ACNPs who were members of an Acute Care } \\
\text { Nurse Practitioner Network social media site. } \\
\text { Respondents were eligible to participate if they } \\
\text { met the following inclusion. The sample was } \\
\text { predominantly white women between } 41 \text { and } 50 \\
\text { years old. Fifteen states and Puerto Rico were } \\
\text { represented. Most participants had a master of } \\
\text { science degree in nursing. Eighty-two percent } \\
\text { had more than } 5 \text { years of nursing experience, } \\
\text { and } 75 \% \text { had more than } 5 \text { years of nursing } \\
\text { experience in an ICU or ED. }\end{array}$ \\
\hline
\end{tabular}

This cross-sectional descriptive study used a written questionnaire consisting of 32 items, two of which contained 25 sub items

arate

This study demonstrated that greater professional autonomy in the workplace is critical factor in turnover intention in novice NPs in the PC setting. Multiple regression results from the main study variables showed having greater professional autonomy reduced turnover intention. Autonomy to be the most influential factor in NP job satisfaction factor in NP job satisfaction. The results of the standard multiple regression model indicated that the variables most predictive of turnover intention were professional autonomy $(p=.001)$ and role ambiguity $(p=.03)$. The model accounted for approximately $48 \%$ of the variance in turnover intention $\left(R^{2}=\right.$ .476).professional autonomy remained significant $(\beta=-.44, t=-3.42, p=.001)$ and role ambiguity was significant $(\beta=-.20, t=-2.14, p=.03)$. Self-confidence and perceived competence was a significant predictor of turnover $(\beta=-.29, t=3.95, p<$ $.001)$.

Prior RN experience ranged from 0 to 38 years with a mean of 13.8 years. This variable was positively skewed; Prior PJSI experience had a non-significant
relationship with NP role transition $(r=-.08, p=.12)$. Additional analyses using various cut points within the RN experience variable revealed no significant relationships with NP role transition. In the first NP position, $33 \%$ of participants received a formal orientation Receiving a formal orientation was positively correlated with NP role transition $(r=.29, p<.001)$.

Forty-six percent of the respondents reported experiencing stress, with job performance. Statistically significant positive correlations were found among organizational support. The relationship between communication/leadership was also and personal finances reported as the top 2 stressors. Comfort/confidence $(r=$ $0.49 ; p<.01)$, patient safety $(r=0.38 ; p<.05)$, professional satisfaction $(r=0.72 ; p$ $<.05$ ), and job satisfaction. No significant differences were found between nurses with 0 to 4 years and nurses with more than 4 years of ICU/ED experience in the

descriptive, correlational-comparative design measures of personal and community $(r=0.53 ; p<.01)$. The community resource of organizational support and communication/leadership were related to successful transition (comfort/confidence, patient safety, and professional and job satisfaction) for ACNPs during their first 6 months of practice. Support from the nurse practitioner/physician mentor and their availability for new situations and procedures was deemed important by the new ACNPs. Feedback about their work was important and helped the ACNPs to develop confidence in their assessment and diagnostic skills. Support from families and friends during this time frame was also important.

The themes identified were: loss of personal control of time (personal time) and privacy; changes and losses in relationships (Professional relationship changes ( Physicians as mentors and supporters builds NP confidence) (Nurses a barrier

Kelly, N., \& 21 recent NP graduate. The age range 33-52 Mathews, years. Practicing in Central Illinois

Qualitative descriptive study

35 newly graduated primary care nurse practitioners during their first year of practice. 33 from master program, 2 from certificate

Brown \&

Olshansky, (1998) programs. Employment settings clinics, public health dept. private practices the VA hospital $94 \%$ white, $6 \%$ Asian

Twenty-three graduates of NP program options at two universities in the western U.S.

Jones J. et al at two universities in the western U.S. , (2014) interviews in the western U.S. participated in focus group discussions or interviews

Heitz L. J.

et al. (2004) The sample consisted of 8 FNP

Qualitative descriptive

Qualitative Grounded theory feeling of separation); feelings of isolation( Pioneer in practice) and uncertainty in establishing the NP role(role ambiguity-different scope in defend states, learning new knowledge keeping update); and a special bonding with clients. Coping Strategies-developing professional social network.

Stages of development include laying the foundation (recuperating from school, negotiating the bureaucracy, looking for a Job, and worrying); launching (feeling negotiating the bureaucracy, looking for a Job, and worrying); launching (feeling
real, getting through the day, battling time, and confronting anxiety); meeting the challenge (increasing competence, gaining confidence, and acknowledging system problems); and broadening the perspective (developing system savvy, affirming oneself, and upping the ante).

Four main domains emerged from analysis of qualitative data: a) "Getting your boots on and getting into the role"; (b) "Older people are more complex than we were prepared to care for"; (c) "It is very different as a provider, but I am so glad I was a nurse with experience first"; (d) "NPs have a scope of practice, physician assistants (PAs) have a job description-but I wish we had their [procedural] preparation."

Two phases of role transition occurred and were depicted by the central categories that emerged: extrinsic obstacles, intrinsic obstacles, turbulence, positive extrinsic forces, positive intrinsic forces, and role development. Although the central categories were found to be the same in Phase I and Phase II.

Three themes evolved from the data. The study's themes were that nursing philosophy differed from medical philosophy, difficulties and barriers were evident as NPs established their profession in a Canadian rural province, and despite barriers NPs had a sense of excitement and pride in their work. Systems' challenges were evident when insurance companies did not recognize NPs and employment with physicians who integrate the fee-for-service model. NPs described the major barrier as physicians viewing NPs as a threat because they could lose patients and personal income to NPs. Therefore, NPs preferred to work in salaried positions without limitations rather than with physicians who use the fee-for-service model. More system challenges included the inability to prescribe narcotics, clients not open to seeing a NP provider, and lack of referral acceptance by specialists. Despite getting a referral from an NP, specialists often referred patients back to the physician instead of the NP the physician could receive a higher reimbursement for the patients' visit.

Four themes emerged that depicted a linear progression of the transition process from school preparation to beginning feelings in the new role and then development into a more confident practice. Themes 1. First impression I am prepared? Theme 2 Transition. Theme 3: making as a real NP. Theme 4: the helper and the hinders. (2008) $\begin{array}{ll}\text { Cusson \& } & \text { A convenience sample of NNPs was recruited } \\ \text { Strange } & \text { using list servs and postal mailings. Responses }\end{array}$ were returned by 70 NNP
Qualitative descriptive 
This is the point at which the FNP graduate emerges from Phase II into an independent provider. Positive forces and obstacles occurred during the role transition. Learning environments that support critical thinking and synthesis of information facilitate role transition.

Cusson and Strange ${ }^{[10]}$ conducted a qualitative descriptive survey study. The purpose of the study was to explore the transition of neonatal NPs during their first year of clinical practice. The first theme was the first impression: I am prepared. Many emotions were described, included feelings of fear and insecurity. The second theme was the transition. Feelings of self-confidence were cited as an important factor during transition. The NPs would repeatedly revert back to the staff nurse role or sometimes felt very critical of staff nurse performance. The type and length of orientation or onboarding to role was a significant factor in achieving confidence. Support from physicians was found to assist in the transition and improve self-confidence. The third theme identified was making it as a real NP that is, being able to handle the role and effectively make decisions on their own without verification or validation from physicians or other providers. The last theme identified was the helper and the hinders. Poor professional relationships with staff nurses, unit leaders, and physicians were reported to hinder transitions. Supportive relationships were key to the transition process.

Barnes $^{[11]}$ conducted a descriptive, cross-sectional study. The purpose was to examine the relationships between NP role transition, prior RN experience, and a formal orientation. The convenience sample was composed of 352 participants who attended a national NP conference. Participants were asked to rate their agreement or disagreement with statements about feelings of support versus isolation; understanding of the NP role by patients, physicians, and other staff; and feeling prepared to manage patients and time. Prior RN experience and receiving a formal orientation in the first NP position were measured with single-item questions. Prior RN experience ranged from 0 to 38 years (mean: 13.8 years). Prior experience had a nonsignificant relationship with the NP role transition $(p=.12)$. Thirty-three percent of the participants received a formal orientation in their first NP position. Receiving a formal orientation was positively correlated with NP role transition $(p<.001)$.

\subsection{Nurse practitioner perception of preparedness}

The NP role has continued to emerge and evolve around the world. Education, training, credentialing and scope of practice for NPs vary by country. Depending on where each country is in this evolution process, this may define the goals for understanding the effectiveness of their required training. With the passage of the Affordable Care Act (ACA), a new healthcare bill to make affordable health insurance available to more people, an additional 17 to 20 million Americans gained access to health insurance. ${ }^{[12]}$ The ACA was expected to result in an increase in 20 million additional initial care visits nationwide. ${ }^{[12]}$ Prior to the new US administration, it was believed by 2020 that more than 30 million Americans would gain health insurance under this act. Now with ongoing changes to the act and uncertainties, these numbers may vary depending on new health care policy initiatives. What we do know is that people will need more access to health care services, including those provided by Advanced Practice Registered Nurses. A survey conducted by the ICN International Nurse Practitioner/Advanced Practice Nursing Network (INPAPNN) found that 32 countries indicated the presence of a nursing role requiring education beyond that of a licensed or Registered Nurse. ${ }^{[13]}$ Roodbol $^{[14]}$ reported that over sixty countries identified, have develop or have an interest in advanced nursing roles. However, further clarification of what these roles will provide and what qualifications for practice they require remain unclear from a global point of view. However, proper transition to advanced practice nursing is fundamental to improved patient outcomes. The educational preparedness of student NPs is foundational in the transition process. According to the IOM, ${ }^{[5]}$ nurses should obtain the highest level of education and training through an academic system that promotes academic improvement. Obtaining effective and quality education to function in the NP role is the first stage of the transition from a student NP to an employed NP. Heitz et al. ${ }^{[7]}$ stated that the transition begins during the education phase and extends into the postgraduate NP phase. Advanced practice nurse preparedness is a key aspect of the NP role transition.

Jones et al. ${ }^{[15]}$ conducted a qualitative descriptive study to explore NP graduate perceptions of the adequacy of their education to prepare them to care for seniors. Twenty-three graduates of an NP program from 2 universities in the western United States from the same parent system participated in focus group discussions or interviews. Both programs had adult NPs and family NPs. The aim of the study was to describe the successes and limitations of NP programs in preparing graduates to care for older adults, and to identify strategies and direction to enhance the older adult curriculum. All students were asked to attend. Four main themes emerged from the analysis of qualitative data. The first was identified as "Getting your boots on and getting into the role." Graduates described feelings of insecurity and a lack preparation to care for this patient population and a lack of preparation for their new role. Establishing mentor relationships, using technology to fill gaps not provided in their NP course, and training about caring for older adults facilitated confidence. 
The second theme identified was "Older people are more complex than we were prepared to care for." Graduates felt a need for greater exposure to meaningful clinical experiences with older adults. The third theme identified was "It is very different as a provider, but I am so glad I was a nurse with experience first." There were varying ranges of prior $\mathrm{RN}$ experience. Those with more prior experience relied on their prior nursing experience to care for these patients. The participants perceived that prior experience helped fill gaps in the NP education. The last theme identified was "NPs have a scope of practice, physician assistants (PAs) have a job description-but I wish we had their procedural preparation." Some of the participants shared the perception that PA education was superior to NP education.

Hart and Macnee ${ }^{[16]}$ conducted a cross-sectional descriptive study that used a written questionnaire consisting of 32 items, 2 of which contained 25 sub-items. The questionnaires were administered to attendees at 2 large national NP conferences in 2004. A total of 562 questionnaires were completed and used in the analysis. The purpose of this study was to evaluate the perceived preparedness of NPs for practice after they had completed their basic NP educational programs. A written questionnaire was given to all participants. The questionnaire contained items related to feelings of competency, preparation after completing NP education, and the need for consolation during the first year of NP practice. Only $10 \%$ of the sample perceived that they were very well prepared for practice as an NP after completing their basic NP education. Fifty-one percent perceived that they were only somewhat or minimally prepared. Thirty-eight percent believed that they were generally well prepared. Respondents expressed a desire for increased rigor in NP education, including more clinically relevant information and more experienced faculty. According to Hart and Macnee, ${ }^{[16]}$ NP programs have accredited curricula but limited clinical sites. The programs lack standardization although competencies are mandated. The study revealed that NPs would welcome the development of programs that offered students more clinical hours and teaching that reinforces concepts of health care. ${ }^{[16]}$

\subsection{Nurse practitioner perceived challenges}

During the transition from student to provider, the NP has challenges to meet and obstacles to overcome. Personal and environmental factors may support the transition. Emotional and professional intrinsic factors may have a great impact on new NPs in their first year of practice. Gould et al. ${ }^{[17]}$ conducted a qualitative study to investigate NP experiences 1 year after they first began working in a mostly rural Canadian province. Seven NPs working in New Brunswick were interviewed. The majority of NPs had been licensed within the past 2 years. All of the NPs interviewed were primary health care practitioners, with 6 currently working in community health centers and 1 in private practice. Data were collected by using a semi-structured interview format. The interviews lasted approximately 45 minutes. Repeating topics were recognized and exemplars of each topic identified. Finally, overarching themes were identified. A qualitative analysis was conducted by using the methodology described by Attride-Stirling. ${ }^{[18]}$ Three themes evolved from the data. They found that nursing philosophy differed from medical philosophy, that difficulties and barriers were evident as NPs established their profession, and that despite these barriers NPs had a sense of excitement and pride in their work. How they were compared to physicians was a challenge. Systems challenges were evident when insurance companies did not recognize NPs and when employed with physicians who integrated the fee-for-service model. NPs described the major barrier as physicians viewing NPs as a threat because they could lose patients and personal income to NPs. Therefore, NPs preferred to work in salaried positions without limitations rather than with physicians who used the fee-for-service model. More system challenges included the inability to prescribe narcotics, clients who were not open to seeing a NP provider, and a lack of referral acceptance by specialists. Despite getting a referral from an NP, specialists often referred patients back to a physician instead of the NP, because the physician could receive a higher reimbursement for the patient's visit.

Faraz $^{[19]}$ conducted a descriptive, cross-sectional study. A convenience sample of 177 NPs practicing in primary care settings was recruited through all Commission on Collegiate Nursing Education (CCNE)-accredited master's nursing programs, social media sites, and snowballing. A total of $29 \mathrm{NP}$ educational programs from all regions of the United States and 5 NP residency/fellowship programs forwarded the email to their graduates. The purpose of study was to describe the individual characteristics, role acquisition, and job satisfaction of novice NPs and to identify factors associated with their successful transition and turnover intention in the first year of primary care practice. A survey and questionnaire was sent that included 6 previously established scales and investigator-developed demographic questions. The scales focused on role acquisition, job satisfaction, turnover intention, self-confidence, social support, educational background, and prior work experience. With the exception of the demographic, educational background, and prior work experience questions, the questionnaire utilized Likert-type scales. The results of the study demonstrated that greater professional autonomy in the workplace is a critical factor in turnover intention in novice NPs in the primary care setting. Multiple 
regression results from the main study variables showed that having greater autonomy reduced turnover intention. Autonomy was the most influential factor in NP job satisfaction. Self-confidence and perceived competence was a significant predictor of turnover $(\beta=-.29, t=-3.95, p<.001)$.

Dillon et al. ${ }^{[20]}$ conducted a descriptive, correlationalcomparative study. The study included a convenience sample of 34 ACNPs who were members of an American College of Nurse Practitioners network social media site. The purpose of the study was to identify factors that influence ACNP transition into practice in their first position after graduation; to identify the relationships among personal resources, community resources, successful transition, and job retention; to identify the difference between ACNPs with 0 to 4 years and ACNPs with more than 4 years of prior experience as RNs in an intensive care unit or emergency department; and to determine the skills or procedures that ACNPs found difficult to perform independently. Participants were recruited through an introductory cover letter on the American College of Nurse Practitioners network's social media site. Fortysix percent of the respondents reported experiencing stress associated with job performance. Stressors were identified as lack of effective communication with leadership and organizational or institutional support and personal finances. Successful transition was identified by comfort and confidence in the role $(r=0.49 ; p<.01)$, providing patient safety $(r=0.38 ; p<.05)$, professional satisfaction $(r=.72 ; p<$ $.05)$, and job satisfaction. No significant differences were found between nurses with 0 to 4 years and nurses with more than 4 years of experience in an intensive care unit or emergency department. Having the community resources of organizational support and effective communication with leadership were also related to successful transition. Support from the NP or physician mentor and their availability for new situations and procedures was deemed important by the new ACNPs. Feedback about their work was important and helped the ACNPs to develop confidence in their assessment and diagnostic skills. Receiving support from families and friends was also important. Fifty-two percent of the participants remained in their position for 2 years. The reason for retention or turnover was not identified in the results.

\section{Discussion}

The aim of the literature review was to gain a better understanding of current knowledge about NP transition experience and to apply that knowledge to better support the transition from new graduate to competent NP. The results of the review revealed many factors that influence transition to practice. Three key categories were identified as elements impacting transition into practice. Role transition, perception of NP preparedness, and perceived challenges.

Role transition was identified as the first component because the literature review revealed the first year of work experience is very important in order to expand on the knowledge base that was established during master's education. It is during this first year that many of the skills and the knowledge gained during graduate education are practiced and reinforced. ${ }^{[6]}$ The NPs in the Brown \& Olshansky ${ }^{[6]}$ study described this adjustment period as difficult and stated that they often felt like imposters or they were "faking it" The NPs also described that they have "difficulty 'feeling real",.[6] During this adjustment period many of the NPs reported finding it difficult to make the transition from that of an experienced RN to a novice NP. The new role as an NP is one in which there is more autonomy and advanced decision making. Self-confidence and autonomy seem were identified as consistent factors to assist in role transition. Unsuccessful adjustment could impact self-confidence and impair development of the new role.

How a new NP perceives their preparation and training for practice was a second key component revealed. In Jones et al. ${ }^{[15]}$ graduates felt a need for greater exposure to meaningful clinical experiences. The new NP recognized there was a major difference as a new provider. NPs did not feel prepared and would have liked more training. NPs with significant prior RN experience relied a lot on their prior nursing experience to fill gaps in their knowledge. Both Brown and Olshansky ${ }^{[6]}$ and Heitz et al. ${ }^{[7]}$ revealed that self-confidence and role identity were major factors in the transition experience. These results may indicate that prior nursing experience may not necessarily be an important component of successful entry into practice. Providing opportunities for new NPs to develop skills and to build their self-confidence will better prepare them for practice. Lack of self-confidence can impede competency as the novice NP transitions into his or her new role. However, the available literature does not overtly specify the prior nursing experience needed for effective NP role transition. Experience is believed to be important for skill acquisition and developing competency in nursing practice. Barnes ${ }^{[11]}$ revealed that prior $\mathrm{RN}$ experience could provide a foundation and helped to facilitate the transition into the NP role. NPs with less RN experience were thought to require more time to transition into the new role. The average clinical hours required by most NP programs is 500 to 600 hours. NPs generally rotate with 3 to 4 preceptors during their graduate education. Heitz et al. ${ }^{\text {[7] }}$ and Cusson and Strange ${ }^{[10]}$ supported that lack of effective mentorship could impact self-confidence. NPs have intensive graduate education and clinical training that should prepare them to enter practice prepared to provide safe, high-quality 
care. ${ }^{[16]}$ However, they still report that they are not prepared for practice. With the demanding role of the provider in this current health climate, should we require more intensive training to bridge the transition from student NP to independent NP? At a time when health care reform is rapidly evolving, it is critical that NPs are seen as reliable, competent professionals.

The last major component identified was challenges the NPs perceived when entering practice. Personal and environmental factors had an effect on their transition. The inability to perform certain job duties because clients were not open to seeing a NP provider and other stressors identified were lack of effective communication with leadership and organizational or institutional support. Dillon et al. ${ }^{[20]}$ revealed the lack of support from the NP or physician mentor and their availability for new situations and procedures was deemed important. Establishing one's role identity as an NP, developing professional relationships, and having effective mentorship are key influences on the transition process of the novice NP. The most dominant concerns included applying for licensure and developing new relationships with coworkers and patients who many not be familiar with the role of the NP. All though not revealed in the literature review challenges to NP role transition internationally could include limited access to structured educational programs, insufficient nursing education, a broader focus on the medical model, and lack of respect toward the nursing profession, and issues surrounding intercountry credentialing. ${ }^{[21]}$

As the NP role continues to evolve around the world, developing structured transition programs is an ideal strategy to address some of the barriers and obstacles new NPs face. According Heitz et al. ${ }^{[7]}$ the transition begins during the education phase and extends into the postgraduate NP phase. These programs may be able to facilitate the transition experience after graduation and give students the opportunity to identify a mentor to model behavior after and increase their exposure to clinical situations, which may improve their selfconfidence. Proper transition to advanced practice nursing is fundamental to improved patient outcomes. Novice NPs are routinely expected to assume practice as a full peer with other members of an interdisciplinary team, yet our models for training do not support this expectation as they still rely on the hiring institution to support transition into practice. A well-designed program can facilitate the professional transition of the novice NP into an independent and confident provider.

\section{Conclusion}

Transition into advanced practice nursing is a difficult adjustment. The goal is to provide all new providers with a foundation and resources to help with this process. Understanding the transition experience and the factors that influence this experience will only better prepare advanced practice nurses to provide the highest quality care regardless of specialty and work environment. The ultimate goal being to help ensure improved patient outcomes. Internships or residencies seem to be a great avenue to prepare providers to assume that autonomous role. ${ }^{[4]}$ Ineffective transition to practice can lead to ineffective delivery of quality health care. ${ }^{[22]}$ Future studies that focus on the transition experience after internships and residency programs are needed to establish baseline nursing experiences for entry into NP positions and to develop the knowledge needed to implement and evaluate new educational programs for graduate NPs to improve their transition to independent practice.

\section{REFERENCES}

[1] NP Facts [Internet]. American Association of Nurse Practitioners; c2016 [cited 2017 Mar 29]. Available from: http://www . aanp.o rg/images/documents/about-nps/npfacts.pdf

[2] Kleinpell R, Goolsby M. American Academy of Nurse Practitioner National Nurse Practitioner Sample Survey: focus on acute care. J Am Acad Nurse Pract. 2006; 18: 393-394. PMid:16958768 https://doi.org/10.1111/j.1745-7599.2006.00154.x

[3] Harris C. Bridging the gap between acute care nurse practitioner education and practice: the need for postgraduate residency programs. J Nurse Pract. 2014 May; 10(5): 331-336. https://doi.org/10.1 016/j.nurpra.2014.03.003

[4] Wiltse N, Kelly L, Fairman J. Postgraduate nurse practitioner residency program supporting transition into practice. Acad Med. 2015; 90(6): 707-709. PMid:25551860 https ://doi .org/10.1097/AC M. 0000000000000567
[5] Institute of Medicine. The Future of Nursing: Leading the Change, Advancing Health. Washington (DC): The National Academies Press; 2011.

[6] Brown M, Olshansky E. From limbo to legitimacy: a theoretical model of the transition to the primary care nurse practitioner role. Nurs Res. 1997; 46(1): 46-51. PMid:9024424 https://doi.org/ 10.1097/00006199-199701000-00008

[7] Heitz LJ, Steiner SH, Burman ME. RN to FNP: a qualitative study of role transition. J Nurs Educ. 2004; 43(9): 416-420. PMid:15478695

[8] Brykczynski K. Role development of the advanced practice nurse. In: Hamiric AB, Spross JA, Handson CM, eds. Advanced Nursing Practice: An Integrative Approach. Philadelphia (PA): Saunders; 2000; 107-133 p.

[9] Kelly NR, Matthews M. The transition to first position as a nurse practitioner. J Nurs Educ. 2001; 40(4): 156-162. PMid:11324832

[10] Cusson RM, Strange SN. Neonatal nurse practitioner role transition: 
the process of retaining expert status. J Perinat Neonatal Nurs. 2008; 22(4): 329-337. PMid:19011499 https ://doi.org/10.1097/01 . JPN . 0000341365.60693.39

[11] Barnes H. Exploring the factors that influence nurse practitioner role transition. J Nurse Pract. 2015; 11(Health Policy): 178-183.

[12] Levy J. In U.S. uninsured rate sinks to $13.4 \%$ in second quarter [Internet]. Washington: Gallup; c2014 [cited 2017 Mar 30]. Available from: http://www.gallup.com/poll/172403/unins ured-rate-sinks-second-quarter.aspx

[13] Pulcini J, Jelic M, Gul R, et al. An International Survey on Advanced Practice Nursing Education, Practice, and Regulation. Journal of Nursing Scholarship. 2010; 42: 31-39.

[14] Roodbol P. Survey Results Presented for the ICN International Nurse Practitioner/Advanced Practice Nursing Conference, 2004 Groningen, Netherlands.

[15] Jones J, Kotthoff-Burrell E, Kasss-Wolff J, et al. Nurse practitioner graduates 'Speak Out' about the adequacy of their educational preparation to care for older adults: a qualitative study. J Am Assoc Nurse Pract. 2015; 27(12): 689-706. https : //doi.org/10.1002/2327 $-6924.12230$

[16] Hart A, Macnee CL. How well are nurse practitioners prepared for practice: results of a 2004 questionnaire study. J Am Acad Nurse
Pract. 2007; 19(1): 35-42. https://doi.org/10.1111/j.1745 $-7599.2006 .00191 . \mathrm{x}$

[17] Gould ON, Johnstone D, Wasylkiw L. Nurse practitioners in Canada: beginnings, benefits, and barriers. J Am Acad Nurse Pract. 2007; 19(4): 165. https://doi.org/10.1111/j.1745-7599.2007.0 0210. $\mathrm{x}$

[18] Attride-Stirling J. Thematic networks: an analytic tool for qualitative research. Qualitative Research. 2001; 1: 385-4050. https : //doi.org/10.1177/146879410100100307

[19] Faraz A. Novice nurse practitioner workforce transition and turnover intention in primary care. J Am Assoc Nurse Pract. 2017; 29(1): 26-34. https ://doi.org/10.1002/2327-6924.12381

[20] Dillon DL, Dolansky MA, Casey K, et al. Factors related to successful transition to practice for acute care nurse practitioners. AACN Adv Crit Care. 2016; 27(2): 173-182. PMid:27153306 https://doi.org/10.4037/aacnacc2016619

[21] Schober M, Affara F. Advanced practice nursing. 2006. Malden , MA: Blackwell.

[22] Hain D, Fleck L. Barriers to nurse practitioner practice that impact healthcare redesign. Online J Issues Nurs. 2014; 19(2): 2. PMid:26824837 